\title{
Socio-ecological determinants of distress in Filipino adults during COVID-19 crisis
}

\author{
John Jamir Benzon R. Aruta ${ }^{1}$ \\ Accepted: 22 December 2020 / Published online: 3 January 2021 \\ (C) Springer Science+Business Media, LLC, part of Springer Nature 2021
}

\begin{abstract}
The present study examined the socio-ecological factors that influenced psychological distress (combined index of depression and anxiety symptoms) among Filipino adults during the COVID-19 crisis. The study involved 401 adult participants currently residing in the Philippines. Data were collected using a self-reported online questionnaire administered to the participants. Findings revealed that one individual level factor, such as individual resilience, and two family level factors, such as safety at home and being a parent, negatively influenced psychological distress. On the other hand, a family level factor, family's financial difficulties, positively predicted psychological distress. Societal level factor such as national resilience, but not the community level factor, community resilience, positively predicted psychological distress in Filipino adults. Findings identified individual resilience, national resilience, and financial difficulties as the strongest predictors of psychological distress among Filipino adults during the COVID-19 crisis. Implications, limitations, and future directions are discussed.
\end{abstract}

Keywords Socio-ecological factors $\cdot$ Psychological distress $\cdot$ Filipinos $\cdot$ COVID-19

\section{Introduction}

\section{COVID-19 Worldwide}

In December 31, 2019, China announced the discovery of the novel coronavirus (COVID-19) in Wuhan. From that point, COVID-19 has quickly spread across the world. By March 11, 2020, the World Health Organization declared COVID-19 as a pandemic (World Health Organization [WHO], 2020). Consequently, its highly contagious nature has affected millions of lives worldwide (WHO, 2020) leading to world leaders putting their respective countries on lockdown with varying degrees of tightness (WHO, 2020). As of the second week of October in 2020, there are $>36$ million confirmed cases and $>1$ million deaths worldwide (WHO, 2020). Corollary to the massive loss of life, the COVID-19 crisis was estimated to precipitate a global economic recession (International Monetary Fund, 2020). Furthermore, the COVID-19 crisis has also led to a spike in the number of individuals experiencing mental health concerns (United Nations [UN], 2020). The present study aims

John Jamir Benzon R. Aruta

aruta_johnjamirbenzon@yahoo.com

1 De La Salle University, 2401 Taft Avenue, Malate, 1004 Manila, Philippines to advance the literature on mental health by examining the socio-ecological predictors of psychological distress during the COVID-19 crisis in the Philippines.

\section{The Philippine Context}

Historically, the Philippines has been constantly facing natural disasters, including typhoons and volcanic eruptions, among others. For example, the country faces more than 20 cyclones every year. In 2018, 21 strong tropical cyclones hit the country which affected thousands of families, killed hundreds of people, damaged thousands of properties, and ruined livelihoods (PAGASA, 2018). Moreover, the eruption of Taal Volcano in January 2020 which is located in the southern part of the Luzon island, has affected the livelihood of thousands of Filipino families (Liu et al., 2020). United Nations University Institute for Environment and Human Security's (UNU-EHS) World Risk Report has consistently listed the Philippines as highly prone in terms of high disaster risk (UNU-EHS, 2011). However, the disasters and adversities that the country has faced in the past only required regional governmental response. It is undeniable that the COVID-19 crisis is the widest adversity that the country has ever faced, which required an unprecedented national level public response.

In the third week of March 2020, the Philippine government implemented varying types of community quarantine 
(lockdown) in which regulation strictness was based on the extent of infection spread in an area ("ECQ and GCQ", 2020). Community quarantine required stopping the operations of non-essential services such as businesses, public transportations, and other operations. Work-from-home and skeletal workforce policies were implemented in public and private sectors, including schools and businesses, to minimize physical contact across the country ("ECQ and GCQ", 2020). The community quarantine in the country, especially in its capital Manila, was implemented for several months and was considered the longest lockdown in the world to date (Yee, 2020). As of the second week of October, the Philippines has $>329,000$ COVID-19 cases, with approximately 6000 deaths, ranking as one of the countries most affected by the COVID-19 crisis worldwide (WHO, 2020). Economically, COVID-19 crisis in the Philippines has resulted in an nationwide unemployment rate of about $18 \%$ (7.3 million job losses) in April 2020 (Philippine Statistics Authority [PSA], 2020). In July 2020, a mobile phone-based survey showed that unemployment has skyrocketed to $46 \%$ (Social Weather Stations [SWS], 2020). Given the scale of adversities that the Philippines is facing, the present study aims to examine Filipino adults' psychological distress and its socio-ecological determinants during the COVID-19 crisis.

\section{COVID-19 Crisis and Mental Health}

Although the vast majority of the population is not expected to suffer directly from the physical symptoms caused by the COVID-19 disease, nobody has immunity from the psychological consequences brought about by the COVID-19 crisis. It was projected that the COVID-19 crisis could lead to a surge in mental health concerns worldwide (UN, 2020). Recent studies showed that the COVID-19 pandemic had caused alarming mental health consequences, including stress, anxiety, and depression, among others, across the world (Lieberoth, Lin, Stockli, Han, et al., 2020; Salari, Hosseinian-Far, Jalali, Vaisi-Raygani, et al., 2020). In the Philippines, the increasing number of COVID-19 infections required long months of community quarantine (Yee, 2020), resulting in prolonged isolation and increase in mental health problems including depression, anxiety, and trauma, among others among Filipinos (Talidong \& Toquero, 2020; Tee, Tee, Anlacan, et al., 2020). Furthermore, living in a developing country can make Filipinos especially vulnerable to the consequences brought about by the COVID-19 crisis. Therefore, it is imperative to investigate the factors within a person's socio-ecological environment which serve as protective factors against and vulnerability for psychological distress among Filipinos within the context of the COVID-19 pandemic.

\section{Socio-Ecological Determinants of Distress}

While previous research focused on individual level factors that influence mental health, there is a dearth of research that takes into account the indirect role of socio-ecological factors on psychological distress. In the present study, individual level factors including age, religiosity, and individual resilience were identified as predictors of psychological distress during the COVID-19 crisis. There is mixed evidence on the relationship between age and psychological distress in times of adversities. For instance, previous findings demonstrated that age has no association with distress among Israeli adults during the aftermath of the second Lebanon war (Kimhi, Eshel, Zysberg, \& Hantman, 2010). On the other hand, recent evidence showed that during times of war and other adversities, older adults in Israel experience less psychological distress, compared to younger adults, due to more refined emotion regulation skills that developed over time (Eshel, Kimhi, Lahad, \& Leykin, 2016). Age differences in psychological distress may vary based on the nature of the disaster. In terms of the COVID-19 pandemic, older individuals are highly at risk to the health threat of coronavirus (Garnier-Crussard, Forestier, Gilbert, and Krolak-Salmon 2020). Religiosity was found to buffer the impact of stressful life events on psychological distress among African American adults (Lesniak, Rudman, Rector, \& Elkin, 2006). Individual resilience, or a person's capacity to recover from life's adversities (Connor \& Davidson, 2003) was found to protect individuals with experience of trauma and abuse against depression (Wingo et al., 2010) and adult Israeli Arabs and Jews from psychological distress during the COVID-19 pandemic (Kimhi, Eshel, Marciano, \& Adini, 2020a).

In terms of family level factors, safety at home, parenthood, and financial difficulties in the family were selected as predictors of psychological distress during the COVID-19 pandemic. Evidence suggests that sense of safety at home in times of stressful life events reduced COVID-19 distress among adult Israeli Jews (Kimhi, Marciano, Eshel, \& Adini, 2020b). Moreover, parenthood or having children was found to boost adults' well-being, meaning in life, life satisfaction, positive emotions (Nelson, Kushlev, \& Lyubomirsky, 2014), and decrease distress during challenging life events (Kimhi, Marciano, et al., 2020b). On the other hand, financial difficulties in the family were found to be a strong predisposing factor for mental health problems, including depression and anxiety (DeForge, Belcher, Orourke, \& Lindsey, 2008; Robbins, Dollard, Armstrong, Kutash, \& Vergon, 2008). Historically, financial difficulties in the Philippines caused Filipinos to live through substandard living conditions causing mental health concerns (Tuason, 2010). In the time of COVID-19 crisis, millions of Filipino families have lost sources of income (PSA, 2020; SWS, 2020).

In terms of community level factor, accumulating evidence points out that community resilience, or people's perception of the community's capacity to withstand disasters (Leykin, Lahad, Cohen, Goldberg, \& Aharonson-Daniel, 2013), can be a protective resource against mental health concerns 
(Kimhi, Eshel, Leykin, \& Lahad, 2017; Kimhi \& Shamai, 2004). For instance, community resilience was found to reduce psychological distress among Israeli adults living in the Israel-Lebanon border who have greater exposure to threats of war (Kimhi \& Shamai, 2004) and among Israeli adults who experienced terror attacks (Kimhi et al., 2017). In addition, national resilience, or a person's perception of the capacity of one's nation to recover from adversities while keeping its social fabric intact (Kimhi, Eshel, Lahad, \& Leykin, 2019), was found to be an important protective factor against distress symptoms in times of great adversities such as wars and terror attacks (Kimhi et al., 2017).

In summary, the above-mentioned socio-ecological factors were selected as predictors of psychological distress due to their important role in determining psychological distress in times of adversities as proven by empirical evidence. The present study aims to advance this line of research by examining how these factors influence psychological distress within a socio-ecological framework among Filipino adults during the COVID-19 crisis.

\section{Theoretical Perspective}

Ecological Systems Theory (Bronfenbrenner, 1979) proposed that there are several environmental systems that influence people's mental health: microsystem, mesosystem, exosystem, macrosystem, and chronosystem. Microsystem (individual and family level factors) includes factors within a person's immediate environment, such as personal and family characteristics. Similar to microsystem, mesosystem (community level factors) includes factors within one's proximal environment, including school, neighborhood, and peers. Exosystem (societal level factors) includes economic, political, and government factors that indirectly influence a person's way of living. Macrosystem involves distant collections of society's overarching cultural beliefs and values that indirectly influence one's development. Lastly, chronosystem (dimension of time) consists of environmental events including transitions throughout a person's life.

Guided by Ecological Systems Theory, the present study investigated the factors within a person's socio-ecological environment that directly and indirectly influenced psychological distress (combined index of depression and anxiety) in the context of COVID-19 crisis in the Philippines. The current research examined the individual, family (microsystem), community (mesosystem), and societal (exosystem) determinants of psychological distress in Filipino adults. Given that the fight against the COVID-19 crisis requires a multilevel response, it is imperative to determine the factors at the different levels of a person's socio-ecological environment that contribute to mental health problems. This is necessary in order to inform more holistic mental health policies and interventions in times of adversities.

\section{Research Objectives and Hypotheses}

To date, no research has been conducted on the socioecological determinants of psychological distress during the COVID-19 pandemic in the Philippines. In light of the foregoing literature, the present study proposed the following hypotheses:

1. In terms of individual level factors, Filipinos who are older, less religious, and have lower individual resilience will report greater levels of psychological distress.

2. In terms of family level factors, Filipinos who have greater financial difficulties in the family, and a lower sense of safety at home will report psychological greater distress. In addition, Filipino adults with no children will report higher levels of psychological distress compared to those who have children.

3. In terms of community level factor, individuals with perception of higher community resilience will experience lower psychological distress.

4. In terms of societal level factor, individuals with perception of greater national resilience will experience lower psychological distress.

\section{Method}

\section{Participants}

The present study collected responses from 401 adults currently residing in the Philippines. There were 254 (63.34\%) females, $146(36.41 \%)$ males, and 1 did not report gender. The participants' ages ranged from 18 to 68 years old $(M$ age $=$ $30.09, S D$ age $=11.15$ ) with more than half of them in the age bracket $22-29$ years $(55.36 \%)$. In terms of civil status, most participants were single (72.57\%). The majority of the participants earned bachelor's degrees $(66.83 \%)$ and more than a third of them reported receiving higher than average income $(39.40 \%)$.

\section{Instruments}

\section{Individual Resilience}

The present study used the 10-item Connor-Davidson Resilience Scale (CD-RISC 10) to measure an individual's capacity to bounce back from the COVID-19 crisis (Campbell-Sills \& Stein, 2007; Connor \& Davidson, 2003). Respondents rated each item (e.g., "Tend to bounce back after an illness or hardship") on a 5-point scale ( $0=$ Not true at all times to $4=$ True nearly all of the time), with a higher score indicating a greater level of individual resilience. CD-RISC 10 
has demonstrated a stable single-factor structural validity based on adult samples in Spain (Blanco, Guisande, Sánchez, Otero, \& Vázquez, 2019) and China (Wang, Shi, Zhang, \& Zhang, 2010). Moreover, previous studies showed an excellent reliability $\alpha=.86$ for CD-RISC 10 (Blanco et al., 2019). In the present study, the reliability index of CD-RISC 10 was $\alpha=.90$.

\section{Community Resilience}

The 10-item Conjoint Community Resilience Assessment Measure (CCRAM-10) was utilized to assess participants' perceptions on the ability of a community to deal with Coronavirus crisis (Leykin et al., 2013). Participants responded to each item (e.g., "The municipal authority functions well in the current Coronavirus crisis.") on a 5-point scale $(1=$ Strongly disagree to $5=$ Strongly agree $)$, with a higher score indicating a greater level of community resilience. Previous studies based on data from adult samples in Israel (Leykin et al., 2013) and China (Cui \& Han, 2019) showed a stable five-factor model (i.e., leadership, collective efficacy, preparedness, place attachment, \& social trust) of the CCRAM-10. The reliability of CCRAM-10 was adequate for all factors and overall scores, ranging from $\alpha=.66$ to $\alpha=$ .86 (Cui \& Han, 2019). In the present study, the overall reliability of CCRAM-10 was $\alpha=.90$.

\section{National Resilience}

National resilience, or one's perception of a nation's capacity to recover from adversities, specifically during the COVID-19 crisis, was measured using a 16-item scale, with 14 items (e.g., "I am optimistic about the future of my country") adapted from the original 25-item NRAS (Kimhi et al., 2019) and the remaining two items ("I have full faith in the ability of my country's health system to care for the population in the current Coronavirus crisis." and "I have complete confidence in the ability of my government to take care of all aspects relevant to overcoming the current Coronavirus crisis.") were developed by Shaul Kimhi and colleagues to increase the content relevance of the scale during the COVID-19 crisis. Participants responded using a 5-point scale $(1=$ Strongly disagree to $5=$ Strongly agree), with a higher score indicating a greater level of national resilience. Recent research using Filipino samples showed stable four factors of national resilience (Callueng, Aruta, Antazo, \& Diato, 2020). Previous studies using Israeli adults demonstrated reliability coefficients of $\alpha=.88$ (Kimhi, Eshel, et al., 2020a) and $\alpha=.91$ (Kimhi, Marciano, et al., 2020b) for national resilience during the COVID-19 pandemic. In the current study, the overall reliability of national resilience was $\alpha=.95$.

\section{Psychological Distress}

The present study measured the severity of participants' distress during the COVID-19 crisis by using the 8-item instrument which was based on the anxiety (e.g., "Lack of calm so that it is impossible to sit in one place") and depression (e.g., "Hopelessness about the future") subscales of the Brief Symptoms Inventory (BSI; Derogatis \& Savitz, 2000; Derogatis \& Spencer, 1982). Respondents responded using a 5 -point scale $(1=$ Not at all to $5=$ To a very great extent $)$ with a higher score indicating more severe distress symptoms. Previous research utilized BSI as a valid and reliable tool in assessing distress symptoms in Filipino (Callueng et al., 2020) and Jewish Israeli (Kimhi et al., 2019) adults. In the current study, CFA solution of the BSI yielded an adequate data fit for a modified single-factor model: $\chi 2=69.21, d f=18, p=.00$, $\mathrm{CFI}=.96, \mathrm{TLI}=.94, \mathrm{SRMR}=.04, \mathrm{RMSEA}=.08$. All items showed strong factor loadings $(\lambda)$, ranging from .51 to .81 . The current research used the combined scores of depression and anxiety items as an index of distress with overall reliability of $\alpha=.90$.

\section{Safety at Home}

Participants reported the extent to which they feel secured at home during the Coronavirus crisis by answering one item ("How safe are you at your home during this period of the Coronavirus crisis?") using a 5-point scale ( $1=$ Not at all to 5 $=$ To a very great extent $)$. Recent studies have used this item in assessing people's sense of safety at home in times of adversities including, during the COVID-19 crisis (Kimhi, Marciano, et al., 2020b).

\section{Financial Difficulties in the Family}

To measure the extent of financial difficulties in one's family brought about by the Coronavirus crisis, participants rated one item ("Do you or your family currently experience financial difficulties due to the Coronavirus crisis [such as unemployment, reduced business activity and so on]?") using a 5-point scale $(1=$ Not at all to $5=$ To a very great extent $)$.

\section{Demographic Variables}

Parenthood was assessed by asking the participants the question, "Do you have children?", where $68.8 \%$ reported having no children, $32 \%$ reported having at least one child, and $0.2 \%$ did not report. Religiosity was measured by asking the participants to describe their religious identity $(1=$ Secular, $2=$ Traditional, $3=$ Religious, $4=$ Very religious). Participants then reported their age and gender. 


\section{Procedures}

The survey materials were translated from English to Filipino, which is the national language of the participants. After securing the informed consent from the participants, they were instructed to complete the online version of the survey. The respondents were invited to participate in the study using convenience and snowball sampling. That is, an online survey link was sent to the participants through social media, private messages, among others. Participants were then asked to forward the link to other adults that may qualify to participate in the study. The participants were recruited during the early phase (between the last week of April and the second week of May in 2020) of community quarantine (lockdown) in the Philippines.

\section{Results}

Table 1 shows the descriptive statistics (mean and standard deviation) of the variables, including the estimate of normality (skewness and kurtosis $<|2|$ ), which indicates approximately normal distribution in all the variables. As shown in Table 2, bivariate correlations indicated that all the predictor variables, except gender, were significantly correlated with psychological distress, and that the directionality of the correlations was in the expected directions. Sizes of the relationships of the predictor variables with psychological distress ranged from low ( -.15 for religiosity) to moderate ( -.40 for individual resilience). Gender was not included in the main analysis as it did not show a significant correlation with psychological distress in the preliminary examination.

Sequential regression analysis was conducted to determine the influence of socio-ecological factors at the individual, family, community, and societal levels on distress. In Step 1 of the regression equation, individual level factors such as age, religiosity, and individual resilience were entered. In Step 2, family level factors such as family's financial difficulties due to Coronavirus crisis, parenthood (having a child/ren or not), and sense of safety at home were added. Step 3 added community resilience as a community level factor; and finally, national resilience was factored in as a societal level factor in Step 4. To determine potential multicollinearity, indices of variance inflation factor (VIF) and tolerance (TOL) from the regression analysis were utilized. As general guidelines, VIF above 10 or TOL below .10 may indicate the presence of multicollinearity of the variables (Oakland, Callueng, \& Harris, 2012). There was no multicollinearity noted in the analysis, with VIFs ranging from 1.01 to 1.86 and TOLs ranging from .53 to .98 .

As summarized in Table 3, results of the regression analysis indicated that in Step 1, the three individual level factors collectively explained approximately $19.9 \%\left(\Delta R^{2}=.199, \Delta F\right.$ $(3,390)=32.23, p \leq .001)$ of the variance in psychological distress. Participants who are younger $(\beta=-.18, t=-3.86, p \leq$ $.001)$ and those with lower individual resilience $(\beta=-.37, t=$ $-7.94, p \leq .001)$ tend to experience greater psychological distress. On the other hand, level of religiosity was not a significant predictor of psychological distress $(\beta=-.08, t=-1.78, p$ $=.059$ ). In Step 2, the addition of family level factors accounted for approximately $5.9 \%$ increase in the variance of psychological distress $\left(\Delta R^{2}=.059, \Delta F(6,387)=22.36\right.$, $p \leq .001)$. People with greater financial difficulties in the family $(\beta=.18, t=4.00, p \leq .001)$, individuals without a child or children $(\beta=-.13, t=-2.38, p \leq .05)$, and those with lower levels of sense of safety at home $(\beta=-.12, t=-2.63, p \leq .01)$ tend to experience greater levels of psychological distress. In Step 3, the addition of a community level factor accounted for approximately .05\% increase in the variance of psychological distress $\left(\Delta R^{2}=.005, \Delta F(7,386)=19.59, p \leq .001\right)$. However, community resilience was not a significant predictor of distress $(\beta=-.08, t=-1.56, p=.12)$. In Step 4 , the addition of a societal level factor accounted for approximately $1.5 \%$ increase in the variance of distress $\left(\Delta R^{2}=.015, \Delta F(8\right.$, $385)=18.48, p \leq .001)$. Individuals with perceptions of higher national resilience tend to experience lower distress $(\beta=-.17$,
Table 1 Descriptive Statistics of the Variables

\begin{tabular}{lllll}
\hline Variables & $M$ & $S D$ & Skewness & Kurtosis \\
\hline 1. Age & 30.06 & 11.15 & 1.373 & 1.125 \\
2. Religiosity & 2.59 & .67 & -.485 & .045 \\
3. Individual Resilience & 3.88 & .58 & -.355 & .258 \\
4. Safety at Home & 3.66 & .85 & -.577 & .485 \\
5. Financial Difficulties & 2.62 & 1.01 & .050 & -.314 \\
6. Community Resilience & 3.44 & .65 & -.363 & .527 \\
7. National Resilience & 3.39 & .89 & -.297 & -.514 \\
8. Distress & 2.37 & .78 & .720 & .456 \\
9. Gender $(f, \%)$ & Male $=146$ & 36.4 & & \\
10. Parenthood $(f, \%)$ & With child/ren $=124$ & 30.9 & &
\end{tabular}


Table 2 Bivariate Correlations of the Variables

\begin{tabular}{|c|c|c|c|c|c|c|c|c|c|}
\hline Variables & 1 & 2 & 3 & 4 & 5 & 6 & 7 & 8 & 9 \\
\hline \multicolumn{10}{|l|}{ 1. Age } \\
\hline 2. Gender & .05 & & & & & & & & \\
\hline 3. Religiosity & .08 & $-.11 *$ & & & & & & & \\
\hline 4. Individual Resilience & $.13^{* *}$ & -.04 & $.14 * *$ & & & & & & \\
\hline 5. Safety at Home & $.17 * *$ & $-.17 *$ & .07 & $.30 * * *$ & & & & & \\
\hline 6. Financial Difficulties & -.07 & .08 & .26 & -.01 & -.07 & & & & \\
\hline 7. Parenthood & $.56^{* * *}$ & -.07 & $.13 * *$ & $.17 * *$ & $.20 * * *$ & .002 & & & \\
\hline 8. Community Resilience & $.18 * * *$ & -.03 & $.25 * * *$ & $.36^{* * * *}$ & $.25 * * *$ & -.02 & $.18 * * *$ & & \\
\hline 9. National Resilience & $.19 * * *$ & -.08 & $.28 * * *$ & $.38 * * *$ & $.24 * * *$ & $.10^{*}$ & $.26 * * *$ & $.62 * * *$ & \\
\hline 10. Distress & $-.23 * * *$ & -.04 & $-.15^{* *}$ & $-.40 * * *$ & $-.28 * * *$ & $.18 * * *$ & $-.26 * * *$ & $-.27 * * *$ & $-.32 * * *$ \\
\hline
\end{tabular}

$* p<.05, * * p<.01, * * * p<.001$

$t=-2.86, p \leq .01)$. However, age did not significantly predict distress $(\beta=-.07, t=-1.35, p=.18)$ when family, community, and societal level factors are added in the regression equation.

In total, the variance of distress explained by the combined levels of socio-ecological factors was approximately $27.7 \%$, with individual resilience, family's financial difficulties, and national resilience as the strongest predictors of psychological distress relative to other variables in the study.

\section{Discussion}

Across the globe, the COVID-19 pandemic has posed serious threats not only to people's health but also to their mental health. The United Nations estimated that the consequences brought about by the COVID-19 pandemic have overwhelmed the different levels of society in many countries, and that the deleterious impact of COVID-19 crisis may be more pronounced in developing nations like the Philippines (Bruckner \& Mollerus, 2020). Due to nationwide community quarantine, the Philippine economy has shut down and millions of Filipinos have lost their jobs (PSA, 2020; SWS, 2020), causing serious problems (e.g., lack of resources for rent, bills, and food) down to family and individual levels. Using Ecological Systems Theory (Bronfenbrenner, 1979), the overarching goal of the current study was to examine the individual, family, community, and societal level determinants of psychological distress in Filipino adults during the COVID-19 crisis. Overall, findings revealed that factors within the individual, family, and societal layers of the socioecological environment predicted psychological distress in Filipino adults during the COVID-19 pandemic. Specifically, findings showed that individual resilience, national resilience, and financial difficulties were the strongest determinants of psychological distress.

\section{Key Findings}

\section{Socio-Ecological Determinants of Psychological Distress}

Individual Level The present study examined the individual level factors that influenced psychological distress during the COVID19 crisis. Findings showed that individuals with higher levels of individual resilience reported lower psychological distress. This finding suggests that people who have a greater capacity to withstand life's adversities tend to experience lower levels of depression and anxiety symptoms caused by the COVID-19 crisis. This finding echoes previous findings showing the protective role of individual resilience in preventing distress in times of adversities (Ben-Zur \& Gilbar, 2011; Cenat, Charles, \& Kebedom, 2020), including the challenges caused by the COVID-19 pandemic (Kimhi, Marciano, et al., 2020b). Contrary to the posited hypothesis, it appears that regardless of age and religiosity, people may experience psychological distress during the COVID-19 crisis. An explanation is that the positive and negative aspects of being old may have counterbalanced its influence on distress. That is, older adults were expected to experience greater distress since they are considered highly vulnerable to COVID-19 illness due to lower immunity and a higher possibility of comorbid illnesses (Chen, Wu, Chen, Yan, et al., 2020). However, the influence of age on psychological distress may have been suppressed because older adults may have developed effective strategies in regulating negative emotions (Zimmermann \& Iwanski, 2014) as a result of years of experience in facing life's adversities (Eshel et al., 2016). In addition, religiosity did not predict distress during the COVID19 crisis. One possible explanation is that the COVID-19 pandemic may have made people realize that everyone could be a potential victim of the contagious disease regardless of economic, racial, and religious background. Overall, partial support for hypothesis 1 was found by showing that an individual level factor, individual resilience, but not age and religiosity, was a significant determinant of lower psychological distress during the COVID-19 pandemic. 
Table 3 Sequential multiple regression on the influence of socio-ecological factors on psychological distress

\begin{tabular}{|c|c|c|c|c|c|c|c|}
\hline Variables & $\mathrm{R}^{2}$ & $\Delta \mathrm{R}^{2}$ & $B$ & $S E B$ & $\beta$ & $t$ & $F$ \\
\hline Step1 & .199 & .199 & & & & & $32.23 * * *$ \\
\hline Intercept & & & 4.91 & .27 & & $18.32 * * *$ & \\
\hline \multicolumn{8}{|l|}{ Individual Level } \\
\hline Age & & & -.01 & .003 & -.18 & $-3.86^{* * *}$ & \\
\hline Religiosity & & & -.10 & .05 & -.08 & -1.78 & \\
\hline Individual Resilience & & & -.49 & .06 & -.37 & $-7.94 * * *$ & \\
\hline Step 2 & .257 & .059 & & & & & $22.36^{* * *}$ \\
\hline Intercept & & & 4.58 & .30 & & $15.43^{* * *}$ & \\
\hline \multicolumn{8}{|l|}{ Individual Level } \\
\hline Age & & & -.005 & .004 & -.08 & -1.47 & \\
\hline Religiosity & & & -.09 & .05 & -.08 & -1.80 & \\
\hline Individual Resilience & & & -.43 & .06 & -.32 & $-6.84 * * *$ & \\
\hline \multicolumn{8}{|l|}{ Family Level } \\
\hline Family's financial difficulties & & & .14 & .03 & .18 & $4.00 * * *$ & \\
\hline Parenthood & & & -.22 & .09 & -.13 & $-2.38^{*}$ & \\
\hline Safety at home & & & -.11 & .04 & -.12 & $-2.63 * *$ & \\
\hline Step 3 & .262 & .005 & & & & & $19.59 * * *$ \\
\hline Intercept & & & 4.70 & .31 & & $15.36 * * *$ & \\
\hline \multicolumn{8}{|l|}{ Individual Level } \\
\hline Age & & & -.005 & .004 & -.07 & -1.36 & \\
\hline Religiosity & & & .08 & .05 & -.07 & -1.45 & \\
\hline Individual Resilience & & & -.40 & 07 & -.30 & $-6.16^{* * *}$ & \\
\hline \multicolumn{8}{|l|}{ Family Level } \\
\hline Family's financial difficulties & & & .14 & .03 & .18 & $3.99 * * *$ & \\
\hline Parenthood & & & -.21 & .09 & -.13 & $-2.33^{*}$ & \\
\hline Safety at home & & & -.11 & .04 & -.11 & $-2.40^{*}$ & \\
\hline \multicolumn{8}{|l|}{ Community Level } \\
\hline Community Resilience & & & -.09 & .06 & -.08 & -1.56 & \\
\hline Step 4 & .277 & .015 & & & & & $18.48 * * *$ \\
\hline Intercept & & & 4.60 & .31 & & $15.07 * * *$ & \\
\hline \multicolumn{8}{|l|}{ Individual Level } \\
\hline Age & & & -.005 & 004 & -.07 & -1.35 & \\
\hline Religiosity & & & -.06 & .05 & -.05 & -1.06 & \\
\hline Individual Resilience & & & -.38 & .07 & -.28 & $-5.76^{* * *}$ & \\
\hline \multicolumn{8}{|l|}{ Family Level } \\
\hline Family's financial difficulties & & & .15 & .03 & .19 & $4.39 * * *$ & \\
\hline Parenthood & & & -.18 & .09 & -.11 & $-1.97 *$ & \\
\hline Safety at home & & & -.09 & .04 & -.11 & $-2.27^{*}$ & \\
\hline \multicolumn{8}{|l|}{ Community Level } \\
\hline Community Resilience & & & .02 & .07 & .01 & 0.24 & \\
\hline \multicolumn{8}{|l|}{ Societal Level } \\
\hline National Resilience & & & -.15 & .05 & -.17 & $-2.86^{* *}$ & \\
\hline
\end{tabular}

Note: $* p \leq .05 ; * * p \leq .01 ; * * * p \leq .001$
Family Level Hypothesis 2 proposed that family level factors, including parenthood and sense of safety at home will negatively influence psychological distress. On the other hand, one's family's financial difficulties due to the COVID-19 crisis will positively predict psychological distress. Current findings found support for hypothesis 2 by demonstrating that participants with children tend to report lower levels of depression and anxiety symptoms compared to participants without children. Given that the relationships between childlessness, mental health, and well-being are complex and 
contextual (Umberson, Pudrovska, \& Reczek, 2010), the present study contributes to the literature by demonstrating that in the context of COVID-19 crisis in the Philippines, Filipino adults who have children experienced lower levels of psychological distress despite the challenges during the pandemic. Past evidence posited that parents experience greater meaning in life, satisfaction, and greater positive emotions explaining why parents tend to report less psychological distress (Nelson et al., 2014) compared to non-parent participants. Culturally, Filipinos place a high premium on family-centered values (Morillo, Capuno, \& Mendoza, 2013). Despite the weight and pressure of responsibilities that Filipino parents shoulder (Aassve, Goisis, \& Sironi, 2012), it appears that their children serve as a protective factor from severe mental health problems by serving as parents' main sources of joy, inspiration, and meaning (Aassve et al., 2012; Nelson, Kushlev, English, Dunn, \& Lyubomirsky, 2013) in the midst of the pandemic.

Moreover, findings revealed that individuals who have a greater sense of safety at home reported lower levels of psychological distress during the COVID-19 crisis. This finding strengthens the recent evidence that demonstrated that safety at home suppresses distress symptoms in times of great adversities (Eshel \& Kimhi, 2016) including the COVID-19 crisis (Kimhi, Marciano, et al., 2020b). Given that one's safety from COVID-19 depends on adherence to physical distancing measures, and that staying at home is considered as one of the protective measures against the coronavirus, it is understandable that one's sense of safety at home significantly decreases psychological distress during the COVID-19 pandemic. Furthermore, staying at home during the lockdown may have provided opportunities to spend more quality time with one's family as family support could protect people from experiencing severe depression and anxiety (Kimhi et al., 2010).

The present findings demonstrated that people who faced worse financial difficulties in the family brought about by the COVID-19 crisis experienced greater symptoms of sadness and excessive worrying. This finding is consistent with earlier studies which showed that economic difficulties have detrimental effects on mental health (DeForge et al., 2008; Robbins et al., 2008; Utsey \& Constantine, 2008). Due to community quarantine imposed in the Philippines during the pandemic, millions of Filipinos lost their sources of income (PSA, 2020; SWS, 2020). The detrimental influence of financial difficulties on mental health appeared pronounced because the participants in the present study were adults who are likely shouldering family responsibilities. Moreover, the uncertainty of the length of the community may explain greater uncertainties about the family's income leading to excessive worrying and emotional distress.

Overall, the findings confirmed hypothesis 2 that family level factors such as parenthood and safety at home could serve as a protective factor from severe psychological distress. In contrast, financial difficulties in the family can cause greater psychological distress in Filipino adults during the COVID-19 crisis.

Community Level As a community level factor, community resilience was hypothesized to negatively influence psychological distress. The present study did not find support for hypothesis 3 as community resilience did not significantly predict psychological distress. A possible explanation is that although local communities play a crucial role in fighting the pandemic, much of the decision-making in facing the COVID-19 crisis in the Philippines comes from the national government. For example, the guidelines and regulations in the observance of social distancing, curfew implementation, and relief support, among others, are primarily decided by the national government ("ECQ and GCQ", 2020). The whole nation constantly awaits nationwide announcements from the national government as every decision from that level would largely dictate how Filipinos would live their lives in the succeeding months. Additionally, it is possible that the participants view COVID-19 not only as a threat at the community level, but more so at the national and global levels.

Societal Level Hypothesis 4 proposed that the societal level factor, national resilience, will negatively predict psychological distress. Confirming this prediction, the findings revealed that Filipinos who perceive greater levels of national resilience tend to experience lower depression and anxiety symptoms. That is, when individuals believe that the nation as a whole is capable of recovering from the COVID-19 crisis, they are less likely to experience severe sadness, hopelessness, and excessive worries. Viewed differently, people who believe that the nation is not capable of effectively responding to the adversities caused by the COVID-19 crisis are more likely to experience extreme levels of distress, sadness, and worries. This finding provided support for previous research showing that national resilience is associated with lower levels of distress symptoms in the time of large-scale adversities (Kimhi et al., 2017; Kimhi et al., 2019; Kimhi \& Eshel, 2019), as the impact of crises as wide as the COVID-19 crisis in a country depends heavily on the actions taken at the national level.

Interestingly, the present findings revealed that individual resilience, national resilience, and financial difficulties were the strongest determinants of psychological distress among Filipino adults in the days of COVID-19 crisis. These findings suggest that as people face the challenges caused by the COVID-19 pandemic, the personal capacity to cope with life's adversities, society's ability to effectively respond to crises, and the trustworthiness of public institutions could decrease people's vulnerability to depression and anxiety symptoms, confirming previous research (Ben-Zur \& Gilbar, 2011; Cenat et al., 2020; Kimhi et al., 2019; Kimhi, Marciano, et al., 2020b). It appears that resilience, not only at the individual level but also at the societal level, operates as safeguard 
against psychological distress in times of great adversities. On the other hand, individuals facing greater financial consequences of the COVID-19 crisis have a higher risk of developing depression and anxiety, confirming past evidence on the detrimental impact of financial instability on people's mental health (DeForge et al., 2008; Robbins et al., 2008; Utsey \& Constantine, 2008). As discussed in the earlier part of this section, the fact the participants in the current study were adults shouldering family responsibilities, and the exceptionally high unemployment caused by the COVID-19 crisis (PSA, 2020; SWS, 2020) explain why family's financial losses have a strong detrimental impact on the mental health among Filipino adults during the COVID-19 pandemic.

Putting together, findings of the present study indicate that different factors within the socio-ecological environment influenced psychological distress in Filipino adults in the days of COVID-19 crisis. The current findings provided support for the proposition of Ecological Systems Theory (Bronfenbrenner, 1979) that factors within a person's immediate environment (microsystem) are not the only elements that contribute to one's mental health status. The theory argued that there are other layers within a person's broader ecological environment including family, peers, school, community (mesosystem), economic, political, government system (exosystem), overarching beliefs and values (macrosystem), and dimension of time (chronosystem) that indirectly influence an individual's mental health status during times of adversities. The findings of the present research indicate that while an individual level factor such as individual resilience, but not age and religiosity, contributes to lower psychological distress among Filipino adults during the COVID-19 crisis, family level factors such as family's financial difficulties, parenthood, and safety at home also predicted depression and anxiety symptoms. Moreover, the societal level factor, national resilience, but not the community level factor, community resilience, predicted psychological distress. Ecological Systems Theory (Bronfenbrenner, 1979) provided a holistic lens in understanding the dynamic nature of people's mental health by taking into account how individual, family, community, and societal factors simultaneously influence the development of better mental health in times of great adversities. The findings of the present study contributed to the literature by demonstrating that Ecological Systems Theory (Bronfenbrenner, 1979) can be applied in determining the different protective and suppressing factors of psychological distress within Filipino adults' socio-ecological environment in the midst of the COVID-19 pandemic.

\section{Implications}

The present study provides an empirical and practical contribution to the sparse literature on mental health during the COVID-19 crisis in several ways. First, the present study found that lack of safety at home and financial difficulties due to income losses of at least one family member could lead to greater levels of depression and anxiety symptoms in Filipino adults. Hence, it is recommended that effective mechanisms that provide community safety and sustainable financial security to Filipino families during great crises such as the COVID-19 pandemic be considered. Findings of the current research indicate that safety at home and financial security may not only help solve basic material needs, but may also safeguard Filipinos from the inimical psychological consequences of financial problems. Second, despite the challenges that Filipinos faced during the COVID-19 pandemic, two different levels of resiliencies, such as individual and national resilience, emerged as important factors that play as a protective mechanism against severe mental health concerns. Therefore, programs geared toward improving individual resilience may be beneficial by equipping people coping skills in times of challenging life events. In addition, it is imperative that people visibly witness that the nation and its public institutions (i.e., police, health, education, media, and congress sectors) could effectively respond to the challenges caused by the COVID-19 crisis. The current findings indicate that when the nation, government, and public institutions are perceived as trustworthy and competent, it could partly contribute in reducing people's vulnerability for severe mental health problems. Lastly, the current research indicates that being a parent can serve as a protective factor from psychological distress during difficult times as children may serve as sources of meaning and inspiration to overcome life's adversities (Aassve et al., 2012; Nelson et al., 2013). In the context of counseling and psychotherapy, this may be an important finding as providing greater focus on the joy and meaning that children bring into one's life could be beneficial when dealing with parent-clients who present severe depression and anxiety.

\section{Limitations and Future Directions}

The limitations of the present study provides opportunities for future research. First, limited factors at the different levels were utilized in the study. Future research may examine the impact of other important factors (e.g., emotion regulation, economic status, and trust in public institutions) across the various levels of the socio-ecological environment. This can give further insights on the factors that contribute to mental health in times of adversities. Second, the present study focused on Filipino adults and did not claim that the participants are representative samples. Future studies may focus on more representative samples across different developmental levels and Philippine regions. Third, the criterion variable used in the study was psychological distress representing the combined scores of depression and anxiety. It does not represent other possible negative emotional reactions from the COVID-19 crisis. Future studies may focus on other psychological 
reactions such as fear and trauma. Fourth, the present findings showed that community resilience did not predict distress, which was contrary to the posited hypothesis. The study recommends future research to identify the moderators between community resilience and psychological distress. The capacity of one's local community to address crises may play an important role in protecting people from developing distress symptoms in times of adversities. Lastly, current findings indicate that individuals with children experienced lower distress in the days of COVID-19 crisis. However, the present study used a dichotomous measure (i.e., no child versus with child/ren) of parenthood and did not identify when the connection between number of children and distress plateaus. It is possible that having children may not always lead to lower distress because parents who have more children relative to their financial capacity may experience higher pressure in providing for the children's needs, and hence, may experience greater levels of distress. The present study recommends that future researchers consider looking at the interaction between parents' number of children and socioeconomic status on people's psychological distress in times of adversities. Nonetheless, the present study provided novel insights on the importance of taking into account socio-ecological factors in preserving Filipino adults' mental health in times of great adversities such as the COVID-19 pandemic.

Acknowledgments The author would like to thank Judith Paceño for proofreading the manuscript.

\section{Compliance with Ethical Standards}

Conflict of Interest The author/s claimed no conflict of interest in the present study.

Ethics Approval The study was part of a cross-national study approved by the Institutional Review Board of Tel Aviv University, Israel.

Code Availability Data, materials, and codes for analysis can be made available by the author/s upon written request by any party.

\section{References}

Aassve, A., Goisis, A., \& Sironi, M. (2012). Happiness and childbearing across Europe. Social Indicators Research, 108, 65-86. https://doi. org/10.1007/s11205-011-9866-x.

Ben-Zur, H., \& Gilbar, O. (2011). Resilience and distress: Israelis respond to the disengagement from Gaza and the second Lebanese war. Community Mental Health Journal, 47, 551-559. https://doi. org/10.1007/s10597-011-9371-3.

Blanco, V., Guisande, M. A., Sánchez, M. T., Otero, P., \& Vázquez, F. L. (2019). Spanish validation of the 10-item Connor-Davidson resilience scale (CD-RISC 10) with non-professional caregivers. Aging \& Mental Health, 23(2), 183-188. https://doi.org/10.1080/ 13607863.2017.1399340.
Bronfenbrenner, U. (1979). The ecology of human development: Experiments by nature and design. Cambridge: Harvard University Press.

Bruckner, M. \& Mollerus, R. (2020). UN/DESA Policy Brief \#66: COVID-19 and the least developed countries. Retrieved from: https://www.un.org/development/desa/dpad/publication/un-desapolicy-brief-66-covid-1-and-the-least-developed-countries/

Callueng, C., Aruta, J. J. B., Antazo, B., \& Diato, A. (2020). Measurement and antecedents of national resilience in Filipino adults during coronavirus crisis. Journal of Community Psychology, 48, 2608-2624. https://doi.org/10.1002/jcop.22438.

Campbell-Sills, L., \& Stein, M. B. (2007). Psychometric analysis and refinement of the Connor-Davidson resilience scale (CD-RISC): Validation of a 10-item measure of resilience. Journal of Traumatic Stress, 20(6), 1019-1028.

Cenat, J. M., Charles, C. H., \& Kebedom, P. (2020). Multiple traumas, health problems and resilience among Haitian asylum seekers in Canada's 2017 migration crisis: Psychopathology of crossing. Journal of Loss and Trauma, 25(5), 416-437. https://doi.org/10. 1080/15325024.2019.1703610.

Chen, T., Wu, D., Chen, H., Yan, W., ... \& Ning, Q. (2020). Clinical characteristics of 113 deceased patients with coronavirus disease 2019: Retrospective study. BMJ 2020; 368:m1091.

Connor, K. M., \& Davidson, J. R. T. (2003). Development of a new resilience scale: The Connor-Davidson resilience scale $(\mathrm{CD}$ RISC). Depression and Anxiety, 18, 71-82.

Cui, K., \& Han, Z. (2019). Cross-cultural adaptation adaptation and validation of the 10-item conjoint community resiliency assessment measurement in a community-based sample in Southwest China. International Journal of Disaster Risk Science, 10, 439-448. https://doi.org/10.1007/s13753-019-00240-2.

DeForge, B. R., Belcher, J. R., Orourke, M., \& Lindsey, M. A. (2008). Personal resources and homelessness in early life: Predictors of depression in consumers of homeless MultiService Centers. Journal of Loss and Trauma, 13(2-3), 222-242. https://doi.org/10.1080/ 15325020701769105.

Derogatis, L. R., \& Savitz, K. L. (2000). The SCL-90-R and brief symptom inventory (BSI) in primary care. In M. E. Maruish (Ed.), Handbook of psychological assessment in primary care settings (p. 297-334). Lawrence Erlbaum Associates Publishers.

Derogatis, L. R., \& Spencer, P. M. (1982). The brief symptom inventory (BSI): Administration, and procedures manual-I. Baltimore: Clinical Psychometric Research.

ECQ and GCQ Guidelines. (2020). Retrieved from https://www.covid19. gov.ph/ecq-gcq-guidelines/

Eshel, Y., \& Kimhi, S. (2016). Postwar recovery to stress symptoms ratio as a measure of resilience, individual characteristics, sense of danger, and age. Journal of Loss and Trauma, 21(2), 160-177. https:// doi.org/10.1080/15325024.2014.965970.

Eshel, Y., Kimhi, S., Lahad, M., \& Leykin, D. (2016). Individual, community, and national resiliencies and age: Are older people less resilient than younger individuals? American Journal of Geriatric Psychiatry, 24(8), 644-647. https://doi.org/10.1016/j.jagp.2016.03. 002.

Garnier-Crussard, A., Forestier, E., Gilbert, T., \& Krolak-Salmon, P. (2020). Novel coronavirus (COVID-19) epidemic: What are the risks for older patients? Journal of the American Geriatric Society, 68(5), 939-940. https://doi.org/10.1111/jgs.16407.

International Monetary Fund. (2020). The great lockdown: Worst economic downturn since the great depression [Press release]. Retrieved from https://www.imf.org/en/News/Articles/2020/03/23/ pr2098-imf-managing-director-stateetfollowing-a-g20-ministerialcall-on-the-coronavirus-emergency

Kimhi, S., \& Eshel, Y. (2019). Measuring national resilience: A new short version of the scale (NR-13). Journal of Community Psychology, 47, 517-528. https://doi.org/10.1002/jcop.22135. 
Kimhi, S., Eshel, Y., Lahad, M., \& Leykin, D. (2019). National resilience: A new self-report assessment scale. Community Mental Health Journal, 55, 721-731. https://doi.org/10.1007/s10597-0180362-5.

Kimhi, S., Eshel, Y., Leykin, D., \& Lahad, M. (2017). Individual, community, and national resilience in peace time and in the face of terror: A longitudinal study. Journal of Loss and Trauma, 22(8), 698-713. https://doi.org/10.1080/15325024.2017.1391943.

Kimhi, S., Eshel, Y., Marciano, H., \& Adini, B. (2020a). Distress and resilience in the days of COVID-19: Comparing two ethnicities. International Journal of Environmental Research and Public Health, 17, 3956. https://doi.org/10.3390/ijerph17113956.

Kimhi, S., Eshel, Y., Zysberg, L., \& Hantman, S. (2010). Postwar winners and losers in the long run: Determinants of war related stress symptoms and posttraumatic growth. Community Mental Health Journal, 46, 10-19. https://doi.org/10.1007/s10597-009-9183-x.

Kimhi, S., Marciano, H., Eshel, Y., \& Adini, B. (2020b). Recovery from the COVID-19 pandemic: Distress and resilience. International Journal of Disaster Risk Reduction, 50, 101843. https://doi.org/10. 1016/j.ijdrr.2020.101843.

Kimhi, S., \& Shamai, M. (2004). Community resilience and the impact of stress: Adult response to Israel's withdrawal from Lebanon. Journal of Community Psychology, 32, 439-451.

Lesniak, W., Rudman, W., Rector, M., \& Elkin, D. (2006). Psychological distress, stressful life events, and religiosity in younger African American adults. Mental Health, Religion, \& Culture, 9(1), 15-28.

Leykin, D., Lahad, M., Cohen, O., Goldberg, A., \& Aharonson-Daniel, L. (2013). Conjoint community resiliency assessment Measure-28/10 items (CCRAM28 and CCRAM10): A self-report tool for assessing community resilience. American Journal of Community Psychology, 52, 313-323.

Lieberoth, A. Lin, S., Stockli, S., Han, H ... et al. (2020). Stress and worry in the 2020 coronavirus pandemic: Relationships to trust and compliance with preventive measures across $45^{*}$ countries. Royal Society Open Science. https:/www.forskningsdatabasen.dk/ en/catalog/2547433597

Liu, F., Xing, C., Li, J., Wang, B., Chai, J., et al. (2020). Could the recent Taal volcano eruption trigger an El Niño and lead to Eurasian warming? Advances in Atmospheric Sciences, 37, 663-670. https://doi.org/10.1007/s00376-020-2041-z.

Morillo, H. M., Capuno, J. J., \& Mendoza, A. M. (2013). Views and values on family among Filipinos: An empirical exploration. Asian Journal of Social Science, 41(1), 5-28. https://doi.org/10.1163/ 15685314-12341278.

Nelson, S. K., Kushlev, K., English, T., Dunn, E. W., \& Lyubomirsky, S. (2013). In defense of parenthood: Children are associated with more joy than misery. Psychological Science, 12(1), 3-10. https://doi.org/ 10.1177/0956797612447798.

Nelson, S. K., Kushlev, K., \& Lyubomirsky, S. (2014). The pains and pleasures of parenting: When, why, and how is parenthood associated with more or less well-being? Psychological Bulletin, 140(3), 846-895. https://doi.org/10.1037/a0035444.

Oakland, T., Callueng, C., \& Harris, J. G. (2012). The impact of testtaking behaviors on WISC-IV Spanish domain scores in its standardization sample. Journal of Psychoeducational Assessment, 30(2), 139-147. https://doi.org/10.1177/0734282911423358.

Philippine Atmospheric, Geophysical and Astronomical Services Administration (PAGASA) (2018). Tropical cyclone summary. Retrieved from: http://bagong.pagasa.dost.gov.ph/tropical-cyclone/ tropical-cyclone-summary

Philippine Statistics Authority (2020). Employment situation in April 2020. Retrieved from: https://psa.gov.ph/content/employmentsituation-april-2020

Robbins, V., Dollard, N., Armstrong, B. J., Kutash, K., \& Vergon, K. S. (2008). Mental health needs of poor suburban and rural children and their families. Journal of Loss and Trauma, 13(2-3), 94-122. https://doi.org/10.1080/15325020701769170.

Salari, N., Hosseinian-Far, A., Jalali, R., Vaisi-Raygani, A., et al. (2020). Prevalence of stress, anxiety, depression among the general population during the COVID-19 pandemic: A systematic review and meta-analysis. Globalization and Health, 16(57), 57. https://doi.org/10. 1186/s12992-020-00589-w.

Social Weather Stations (2020). SWS July 3-6, 2020 National Mobile Phone Survey - Report No. 16: Adult joblessness rises to recordhigh $45.5 \%$. Retrieved from: http://www.sws.org.ph/swsmain/ generalArtclSrchPage $/$ ?page $=1 \&$ srchprm $=\&$ arttyp $=3 \&$ stdtrng $=$ \&endtrng $=\&$ swityp $=8$

Talidong, K. B., \& Toquero, C. D. (2020). Philippine teachers' practices to deal with anxiety amid COVID-19. Journal of Loss and Trauma, 25, 573-579. https://doi.org/10.1080/15325024.2020.1759225.

Tee, M., Tee, C., Anlacan, J., et al. (2020). Psychological impact of COVID-19 in the Philippines. Journal of Affective Disorders, 277, 379-391. https://doi.org/10.1016/j.jad.2020.08.043.

Tuason, M. T. (2010). The poor in the Philippines: Some insights from psychological research. Psychology and Developing Societies, 22(2), 299-330. https://doi.org/10.1177/097133361002200204.

Umberson, D., Pudrovska, T., \& Reczek, C. (2010). Parenthood, childlessness, and well-being: A life course perspective. Journal of Marriage and Family, 72(3), 612-629. https://doi.org/10.1111/j. 1741-3737.2010.00721.x.

United Nations. (2020). Launch of the policy brief on COVID-19 and mental health. Retrieved from https://www.un.org/en/coronavirus/ mental-health-services-are-essential-part-all-government-responsescovid-19

UNU-EHS (United Nations University - Institute for Environment and Human Security). World Risk Report. (2011). Germany: Bündnis Entwicklung Hilft. URL: http://www.ehs.unu.edu/file/get/9018 [consulted 19 July 2012].

Utsey, S. O., \& Constantine, M. G. (2008). Mediating and moderating effects of racism-related stress on the relation between povertyrelated risk factors and subjective well-being in a community sample of African Americans. Journal of Loss and Trauma, 13(2-3), 186 204. https://doi.org/10.1080/15325020701769204.

Wang, L., Shi, Z., Zhang, Y., \& Zhang, Z. (2010). Psychometric properties of the 10-item Connor-Davidson resilience scale in Chinese earthquake victims. Psychiatry and Clinical Neurosciences, 64, 499-504. https://doi.org/10.1111/j.1440-1819.2010.02130.x.

Wingo, A. P., Wrenn, G., Pelletier, T., Gutman, A. R., Bradley, B., \& Ressler, K. J. (2010). Moderating effects of resilience on depression in individuals with a history of childhood abuse or trauma exposure. Journal of Affective Disorders, 126(3), 411-414.

World Health Organization (WHO). (2020). Coronavirus disease 2019 (COVID-19): Situation report, 122. Retrieved from https://www. who.int/emergencies/diseases/novel-coronavirus-2019/situationreports

World Health Organization. (2020). Mental health and psychosocial considerations during the COVID-19 outbreak. https://www.who.int/ docs/default-source/coronaviruse/mental-health-considerations.pdf

Yee, J. (2020). Longest lockdown, lost opportunities: PH COVID-19 cases go past 300,000 . Inquirer. Net. Retrieved from https:// newsinfo.inquirer.net/1340659/longest-lockdown-lostopportunities-300k-cases

Zimmermann, P., \& Iwanski, A. (2014). Emotion regulation from early adolescence to emerging adulthood and middle adulthood: Age differences, gender differences, and emotion-specific developmental variations. International Journal of Behavioral Development, 38(2), 182-194. https://doi.org/10.1177/0165025413515405.

Publisher's Note Springer Nature remains neutral with regard to jurisdictional claims in published maps and institutional affiliations. 